\title{
Interruptive Events and Team Knowledge Acquisition
}

\author{
Mary E. Zellmer-Bruhn \\ Carlson School of Management, University of Minnesota, 321 19th Avenue South, Minneapolis, Minnesota 55455 \\ mzellmer-bruhn@csom.umn.edu
}

\begin{abstract}
$\mathrm{I}^{\mathrm{n}}$ nterruptions have commonly been viewed as negative and as something for managers to control or limit. In this paper, I explore the relationship between interruptions and acquisition of routines-a form of knowledge- by teams. Recent research suggests that interruptions may play an important role in changing organizational routines, and as such may influence knowledge transfer activities. Results suggest that interruptions influence knowledge transfer effort, and both knowledge transfer effort and interruptions are positively related to the acquisition of new work routines. I conclude with implications for research and practice.

(Team; Knowledge Management; Knowledge Acquisition; Routines; Interruptions)
\end{abstract}

\section{Introduction}

For a host of reasons, including increasing globalization and advances in technology, organizations face increasingly dynamic environments (Brown and Eisenhardt 1998). In part, as a response to these environmental changes, many organizations have adopted structures that increasingly use teams in daily operations (Gordon 1992, Devine et al. 1999). As a result, teams perform many organizational tasks (Mohrman et al. 1995, Thompson et al. 1996, Wageman 1995). Furthermore, large organizations often have multiple teams performing the same or highly similar tasks. In this case, an innovative routine developed in one team needs to be transferred to other teams. Alternatively, useful routines may be developed in other parts of the organization and need to be transferred to these teams. Evidence that learning affects team performance suggests that we need to understand how teams acquire knowledge (Edmondson 1999). Despite potential benefit, scholars know little about knowledge acquisition by teams (Argote 1999).

In dynamic environments, teams often face interruptions in their regular task activity. Using a combination of interviews and survey data, this paper examines how interruptions influence both the effort team members apply to knowledge acquisition activities (for example, searching for new routines) and their actual acquisition of new knowledge. This study measures knowledge in terms of team-level routines and focuses explicitly on the acquisition of knowledge from external sources rather than within team development of new knowledge. Consequently, this study explores part of the knowledge transfer processwhat influences teams to search for new knowledge and then acquire it.

The organizational learning literature emphasizes the importance of knowledge transfer (e.g., Argote 1999, Epple et al. 1991, Hedlund 1994). Likewise the knowledge-based view of the firm (e.g., Conner 1991, Conner and Prahalad 1996, Kogut and Zander 1992) hinges on knowledge development and transfer. Proponents of the knowledge-based view of the firm argue that by identifying and transferring critical or innovative knowledge within the organization, firms avoid redundancies in which multiple units start from the ground up solving the same problems (Nonaka and Takeuchi 1995). These activities also enhance firms' appropriation of rents from internally generated knowledge capital (Szulanski 1996). Numerous inefficiencies may be avoided if critical knowledge is identified within the organization and transferred to 
points where it can be utilized. An example of such inefficiency was provided by a team member in an interview I conducted for this research:

\begin{abstract}
The other day I was talking to this guy-we just happened to be sitting at the same table at lunch-and [name] was there, who heads up [product team] and [product team] and they were talking about a study they were doing. We found out that we had three different teams on this floor doing the same study. So we paid for it three separate times. We've learned it three different times. And so that just opened up the discussion that there needs to be somebody who takes charge of, hey, you know what? [Product team] is doing this; and [product] is in the same market so then they need to share. Remember to share their information with [product team]. We were talking about how many opportunities we missed, just like that.
\end{abstract}

Despite recognition of the value of knowledge transfer, previous research suggests that knowledge transfer is difficult (e.g., Lessard and Zaheer 1996, Ruggles 1998, Szulanski 1996). For example, Ruggles (1998) reported in the results of a survey of 431 organizations that only $13 \%$ of the executives responding thought they were doing well at transferring knowledge within their organizations. Furthermore, our empirical understanding of the processes constituting knowledge transfer is weak (Argote 1999, Huber 1991, Miner and Mezias 1996). The difficulty and lack of understanding surrounding the knowledge transfer process was echoed by team members I interviewed. For example, one noted: "If I've got a [performance problem], I should be talking to [teams that are doing this process well] to figure out how to get better. That's best practice sharing. It doesn't happen, and we don't know exactly why."

Our understanding of knowledge transfer activities at the team level is even less clear because existing research has tended to be macro in focus, examining the movement of knowledge from organization to organization (e.g., Doz 1996), and top-down, examining knowledge identified at high levels and "broadcast" down to subunits. Comparatively less attention has been paid to within-firm knowledge transfer (although notable exceptions exist; see, e.g., Epple et al. 1991, Szulanski 1996), or to the microprocesses involved in lower-level exchanges such as team-level transfer. This is problematic because teams are a particularly important focal point for knowledge management (Argote 1999), indeed, Nonaka points to teams as imperative to the organizational learning process (Nonaka 1994, Nonaka and Takeuchi 1995). Grant (1996) likewise asserts a need to understand knowledge processes at lower levels to fully understand organizational knowledge management.

Existing knowledge transfer research in teams emphasizes within-team knowledge transfer, which has been addressed in the literature on transactive memory (Liang et al. 1995, Wegner 1986), and group process research on knowledge integration (Okhuysen and Eisenhardt 2002). For example, transactive memory research examines how team members store knowledge collectively and how they partition knowledge within team boundaries (e.g., Moreland et al. 1996). Knowledge transfer in general and knowledge acquisition in particular, across team boundaries have received little research attention. This parallels the majority of research on teams where the emphasis is inside team boundaries and not teams' interaction with their external environments (Ancona 1990, Ancona and Caldwell 1992).

Overall, this study contributes to the knowledge management literature by focusing on knowledge acquisition at the team level, and by examining one possible mechanism in the knowledge acquisition process-interruptions. This study also links the literature on group routines (Gersick and Hackman 1990) to the knowledge management literature, and contributes to the group boundary spanning literature (Ancona 1990, Ancona and Caldwell 1992) by examining the role interruptions play in a specific boundary spanning activity—-knowledge acquisition.

\section{Theoretical Background and Hypotheses}

When team members adopt new routines from outside their boundaries, they engage in knowledge acquisition. The organizations' literature includes extensive research on routines (Ashforth and Fried 1988; Levitt and March 1988; March and Simon 1958; Nelson and Winter 1982; Pentland and Rueter 1994; Weick 1992, 1993; Weiss and Ilgen 1985; Winter 1996). 
Some authors argue that most activities in organizations follow routines (Louis and Sutton 1991, Weiss and Ilgen 1985). Teams quickly develop routines and these routines persist (Dougherty 1992; Gersick, 1988, 1989; Gersick and Hackman 1990; Kelly and McGrath 1985). Persistence deepens over time; the longer a decision-making group is together, the less members experiment with new ways to do things (Ancona 1990). An interviewee noted the persistence of routines: "I submit that unless you dedicate your resource, it's a check-the-box mentality... life as it was before."

Pentland and Rueter (1994, p. 492) describe routines as follows: "One might substitute the less value-laden term 'process' for the ambiguous term 'routine,' " and "processes [routines] can be more or less automatic, embody more or less variety, search, and so on." Nelson and Winter (1982, pp. 14-16) suggest that routines range from well-specified technical processes for producing things, to less specific processes like hiring and firing procedures, or policies for R\&D. A team member supported this view, and also the notion that such procedural knowledge can be transferred between teams: "Fundamentally, every business is a set of processes. And you can apply and improve a process. If you have a greater idea over here, [transfer] it."

Routines prove functional by reducing uncertainty, saving time by eliminating the need to deliberate over appropriate action, and thereby improving efficiency (e.g., Cyert and March 1963). Routines also contribute to members' comfort within a group (Gersick and Hackman 1990). Without routines, organizations and groups would not be efficient structures for collective action (March and Simon 1958), however, despite their positive benefits, routines may have dysfunctional consequences. They may reduce the likelihood of innovation, and may hurt performance if applied in inappropriate situations (Gersick and Hackman 1990, Langer 1989, Virany et al. 1992). Furthermore, in the same way decision makers "satisfice" ${ }^{11}$ (March and

\footnotetext{
${ }^{1}$ Satisficing causes teams to settle for the first acceptable solution as opposed to the optimal solution, and "to use existing repertoires of performance programs whenever possible rather than developing novel responses" (Scott 1992, p. 104).
}

Simon 1958), routines may be satisfactory but not optimal. Thus, even under stable conditions, maintaining a routine may limit performance. This potential for negative consequences combined with the possibility that innovative routines exist outside team boundaries make routines an important area of study for knowledge acquisition.

\section{Interruptions and Routines}

Interruptions can disrupt the routine flow of work, and as such interruptions have often carried a negative connotation in organizational behavior research. The self-management and social learning literatures (e.g., Bandura 1977, Manz 1986, Adcock 1971, Kleiner 1992, Lucco 1994) emphasize controlling and minimizing interruptions (e.g., Andrasik and Heimberg 1982). Interruptions can increase job stress (Kirmeyer 1988), have been linked to coordination problems, work overload, and time pressure in teams (Perlow 1999), and may increase processing time and error rates (e.g., Cellier and Eyrolle 1992). Alternatively, interruptions may invoke a "switch" from automatic performance of routines to the conscious information processing involved in acquiring new routines (e.g., Gersick and Hackman 1990, Langer 1989, Louis and Sutton 1991). Interruptions may prompt attention shifts leading to change and innovation (Gersick 1991; Meyer 1982; Okhuysen and Eisenhardt 1997, 2002; Tyre and Orlikowski 1994; Tyre et al. 1996). Tyre et al. (1996) argue that interruptive events "make time" for change by providing actual or perceived "time-outs" from normal activity, thereby focusing activity and triggering change (cf. Okhuysen and Eisenhardt 1997, p. 9). Such interruptions may be important determinants of change in routines.

Gersick's $(1988,1989)$ work on midpoint transitions links interruptions and changes in team routines. Midpoint transitions occur when team members, responding to a deadline, adjust processes midway through their task. Groups in Gersick's studies were more likely to use different strategies and operating processes after the midpoint transition than before. While the midpoint is not an interruption in the sense of an environmental contingency, it functions as an interruption in that the group members interrupt themselves based on time to deadline. Similar results 
exist for knowledge integration. Formal process interventions in groups led to self-induced interruptions in task activities. These interruptions switched attention, and, depending on the nature of the switched attention, to changes in knowledge integration (Okhuysen and Eisenhardt 2002). These studies reveal internal adaptation resulting from interrupts, but neither explicitly examined the role of interruptions in knowledge acquisition from external sources.

Research at the organizational level of analysis on technological adaptation provides further empirical evidence that interruptions may trigger changes in routines. Weick (1990) suggests that when the regular use of technology is interrupted, organizational members experience increased arousal and change the focus of their attention, providing an opportunity for change. Tyre and Orlikowski (1994) provided supporting evidence from three empirical studies of technological adaptation. They found routines were adapted immediately following the installation of a technology. Changes in routines did not occur until an interruptive "trigger" occurred. Tyre and Orlikowski (1994) suggest that "windows of opportunity" for change only occur immediately after installing a new technology or after similarly interruptive events. Installing a new technology interrupted routine work and prompted adaptation of routines. Thus, technological adaptation research provides evidence that interruptions spur change, however, like existing group process research, it examines the effects of interruptions on internal adaptation of routines.

Descriptions of routine behavior range from "mindlessness" (Langer 1979, 1989) to "automatic cognitive processing" to "habits of mind" (Louis and Sutton 1991) to "habitual behavior" (Gersick and Hackman 1990). Teams' acquisition of new routines requires a movement from "mindless" routine behavior to "mindful" change. Taken together, the previous literature suggests that interruptive events will trigger active cognitive processing, and thus, teams experiencing interruptive events are more likely to mindfully examine their routines for potential changes. I suggest that this should have two implications. First, teams experiencing interruptive events mindfully consider their routines. If such consideration leads to dissatisfaction, the group undertakes knowledge acquisition activities such as searching for new routines and transferring routines once found. Overall, the number of interruptions that a group experiences in a given period should increase the likelihood that the group undertakes knowledge transfer efforts. Thus, my first hypothesis is:

Hypothesis 1. In a given time period, interruptive events positively influence knowledge transfer effort.

Second, interruptive events may directly increase the likelihood that a team acquires knowledge. The interruption creates a window of opportunity for change, and thus knowledge acquisition is more likely to occur in periods of greater interruption. The cognitive "pause" created by the interruption may make a team more receptive to picking up a routine that presents itself, even without active search. As noted by Cyert and March (1963) and others (Cohen et al. 1972), organizations have solutions looking for problems. For example, members may talk to members of other teams, without planning to learn about potential routines, and happen on a new routine that they subsequently acquire. Here, the routine presented itself, with no specific search effort on the part of the team. An interruption can create the opportunity for this type of acquisition. This reasoning leads to my second hypothesis.

Нypothesis 2. In a given time period, interruptive events positively influence knowledge acquisition in the form of new routines.

While teams may acquire new routines in periods of greater interruption, it may be the case that it is the active effort applied to knowledge transfer that determines whether or not a team actually obtains a new routine in a given time period, not just the interruption (Feldman 2000, Edmondson et al. 2001). In others words, as noted in Hypothesis 1, the interruption opens a window of opportunity to examine current work methods. The resulting knowledge transfer effort (e.g., active search for new routines, examining existing routines for improvement), not the interrupt itself, increases the chance that a team identifies and acquires new knowledge from external sources. This reasoning suggests that knowledge transfer effort mediates the relationship between interruptions and 
adoption of routines. Thus, I propose:

Нyротнеsis 3. In a given time period, knowledge transfer effort mediates the influence of interruptions on knowledge acquisition in the form of new routines.

\section{Methods}

This study uses data on operational teams in three firms. Using a field study methodology increases the degree to which participants were engaged in their tasks, task performance was consequential, and the impact of interruptions was realistic (McGrath 1984, p. 33). The teams came from three firms in a single industry, pharmaceutical and medical products, which reduces potential industry differences in knowledge transfer activity.

I began with interviews to better understand team knowledge transfer activities, and to aid in measurement development. Interviews ensured that team members would be familiar with the language I used on my survey. I interviewed 98 individuals, representing 46 teams. All interviews were audiotaped and transcribed, resulting in 147 pages of interview excerpts about knowledge transfer. I read these excerpts to determine what language team members used when they described acquisition of new routines. Interviews also indicated that participating firms emphasized team knowledge transfer activities. For example, one interviewee noted the prevalence of knowledge available for acquisition: "Somewhere... the answer to every problem exists. And it's being done with world-class performance." Another interviewee noted the value of knowledge transfer: "I think you can learn a lot from what the other teams are doing, you know, how they are handling business problems, as well as working with R\&D and things like that. So you can cross-pollinate."

\section{Sample and Survey Procedure}

Primary data for hypothesis testing came from a survey of teams in the three organizations. None of these teams participated in the interviews. Organization names are disguised with letters to provide anonymity. I administered surveys to 12 teams in organization A, 11 teams in organization B, and 135 teams in organization $C$, for a total of 158 teams. I included a team in my analyses if I received responses from at least two members. Ninety teams (57\%) had at least 2 responses (representing an overall individual response rate of $26 \%$ ). ${ }^{2}$ Of the 90 teams with at least 2 members responding, within-team responses ranged from 2 people to 12, with an average of 5 people responding per team. This represented withinteam response rates ranging from 14 to $100 \%$. Teams ranged in size from 3 to 21 members with a mean of about 10 . The teams were all ongoing work teams; no time-limited project teams were included. The majority of the teams (74 of 90) were sales and service teams, as well as some cross-functional brand teams, and customer service teams.

Teams had moderate levels of interdependence in their work. For example, the sales and service teams work interdependently to offer sales support and service for a variety of medical diagnostic machines and software. Service engineers within the teams commonly worked together to maintain equipment, and coordinated schedules to cover client needs. Similar coordination took place among sales people, and sales and service people also interacted to address client needs. For example, while an engineer provided service to a machine on site, he or she may learn that the hospital is considering a new equipment purchase from a competitor; communicating this information with sales people on the team and interdependently working to coordinate action and win accounts in these circumstances is crucial for team success. An interviewee noted the value of this interdependence and coordination:

${ }^{2}$ I compared responding teams to the original sample of 158 to check the representativeness of the realized sample. An analysis of variance (ANOVA) indicated that responding teams were not different in terms of size $(F=0.038, n s)$. Chi-square tests using contingency tables (Conover 1980) indicated that the proportion of each of 5 team types in the realized sample is not significantly different from the proportion of team types in the original 158 teams, and that the proportion of teams from each of the 3 organizations in the realized sample is not significantly different from the proportion of teams from each organization in the original 158 teams. Thus, the 90 responding teams do not significantly differ from the original sample by size, team type, or organization. Finally, explicitly controlling for team type and organization did not change the substantive results for the hypotheses tests. 
We're getting more business. Our customers are happier. See, that's from a hard business perspective, the reason we have teams. Because we believe it will get us incremental business, and it does. Take... a field engineer. In the past, we didn't tell them anything. You know, take your screwdriver and go fix the equipment when it breaks. They are now involved in running the entire business. They know what all these numbers mean. They know how they can affect all those numbers. And they know they have the best creative ideas on how to make things better.

I used a combination of on-site administration and mail administration for the surveys. If teams were not available during the site visit or were dispersed geographically, I administered the surveys by mail. When I mailed surveys, I sent survey packs to my primary contact for the team; members directly returned their surveys to me using prepaid mailing envelopes. Surveys were coded to protect the anonymity of respondents. To maximize response rates, instructions emphasized anonymity for individual respondents, and I made two follow-up contacts to nonrespondents. In addition, I made every effort to keep the quality of the responses high. To ensure members employed the same referent when completing the survey, the name of the team appeared prominently at the top of each survey (Rousseau 1985). My hypotheses also limited the time period in question, so the specific month in question appeared at the top of the survey and was repeated within question groups. The specific month was chosen simply as the month just prior to the time I administered the surveys.

\section{Measures}

Dependent Variables. I used a combination of literature review and interview results to develop dependent variables. A number of issues influenced measurement development. First, I wanted to use language to describe routines that would accurately represent the construct but also be meaningful to respondents. Pentland and Rueter (1994) consider the term "process" to be interchangeable with routine, and they provide examples of what they mean by routines. For instance, they described several routines to accomplish the customer service function: the series of behaviors for answering the phone and authorizing a credit card. Interview respondents described these behaviors as "practices." Routines have also been identified as practices in the knowledge transfer literature (Szulanski 1996), so the survey used practice in referring to routines.

In addition, the survey needed to assure that respondents distinguished between individual-level and team-level routines because my focus is on team-level knowledge acquisition. Individual routines affect only individuals and not the behaviors of a significant subgroup of the team, or the behaviors of the team as a whole. The interviews suggested that respondents distinguish between individual- and team-level routines. For example, I conducted an interview with a team developer who provided examples of an individual-level and a team-level routine. For the individual-level routine, she described a productivity-enhancing practice for individual service engineers (SEs):

\begin{abstract}
After an SE completes his work in the field, he must go through a kind of debriefing of the situation and then send it in to the organization electronically. Apparently, many SEs complain that this takes too much of their "home" or "personal" time. Upon examination, it was discovered that many SEs would wait until they had packed up and driven home until they would debrief. When questioned why they did not do them on site, they argued that they had to "up-link" in order to send them in, and that the only feasible place to do that was at home. Some SEs had developed a routine of debriefing on site and saving the file. Then when they got home, they merely had to connect up, upload the file and get off-line-in just a matter of a few minutes. This alternative practice was identified as a best practice and there have been some attempts to communicate it to the entire SE work force. It is not known at this time how many SEs have adopted the practice.
\end{abstract}

Alternatively, she described a team-level routine. This routine concerned the team practice for getting purchase orders in from customers:

\footnotetext{
In most teams, this had been the responsibility of the SEs. However, they were often late and there was often a lot of follow-up work that needed to be done. There was too much diffusion of responsibility. One team changed the entire process, and made one person at the service center in charge of this process. Consequently, the entire team's process was changed. This new process was identified by the [region] as
} 
a best practice and promoted to other teams in the region.

Based upon the interview results and previous research, I define routines as team-level practices executed by multiple actors (team members) and available to conscious scrutiny by team members. ${ }^{3}$ Practices are patterns or sequences of behaviors enacted to accomplish specific tasks. Interview examples of individual-level and team-level practices were included in the survey to enhance the clarity of the construct to respondents.

Knowledge Transfer Effort. This was measured by asking how much effort the team spent in a specified month on a set of eight items answered on a 5 -point scale ranging from $1=$ no effort to $5=$ a very high amount of effort. Sample items include: searching outside the team for practices, implementing new processes adopted from outside sources, and finding out how other teams within your organization complete similar tasks. A complete set of items is available from the author. Team scores were created by averaging individual scale scores by team (reliability 0.96 (alpha)).

Knowledge Acquisition. The second dependent variable is whether or not the team acquired new practices in the specified month. This variable was measured by asking each team member to answer for the specified month: Did the team adopt work practices from outside the team? As noted above, examples of work practices were provided on the survey. This variable was coded 1 if a team member reported adopting new practices in the specified month, and 0 if a team member did not report practice adoption. Because larger teams will by random variation be more likely to have a yes answer by at least 1

\footnotetext{
${ }^{3}$ When I say "consciously available," I do not mean all the time. Because I consider practices to be a type of routine, I do believe that they will typically be enacted without much discussion or deliberation. However, by consciously available, I mean that if asked to reflect on the "way" they do a certain task, a team would be able to identify the basic steps and features of the practice. This view differs from some of the more extreme views of routinized action, which suggests that these patterns of behavior are completely tacit and unavailable to identification by the actors.
}

team member, I used the proportion of team members reporting an adoption as the dependent variable knowledge acquisition. ${ }^{4}$

\section{Interruptions}

I measured interruptions with 13 items developed using a combination of interview results and literature review (Gersick and Hackman 1990, Louis and Sutton 1991, Langer 1989, Tyre and Orlikowski 1994). For example, Gersick and Hackman (1990) theorized a set of interruptive events that may trigger changes in group routines: encountering novelty, experiencing failure, reaching a milestone, receiving an intervention, coping with a structural change, redesigning the task, or changing authority. After assembling a list of possible interruptions identified in the literature, I reviewed interview excerpts to see whether interviewees identified similar interruptions, and to find examples.

Wherever possible, I combined event types to reduce the number of items. Also, I wrote items using general language so the survey questions would be applicable across different types of teams. This process led to a list of 13 interruptions. Example items include: Did the team lose any members? Did the team hold a formal planning session? Did the team have changes in machines, tools, or other technologies? Did the organization experience a restructuring? For each of the 13 items, respondents circled "yes" if the interruption type occurred, and "no" if it did not. "Yes" answers were coded " 1 " and "no" answers were coded " 0. ." I then totaled the number of interruption items answered "yes" by each team member. I created a team score by averaging the individual totals by team. This resulted in a team-level variable that ranged from 0 to 13 . The full set of items is available from the author.

\section{Control Variables}

I included a number of control variables in the analyses. First, I created two dummy variables to capture any unmeasured effects of differences across the three organizations. For example, organizations may

${ }^{4}$ I thank the editors for suggesting this operationalization to account for the effect of team size in the dependent variable. 
vary in the degree to which they emphasize codification of knowledge. Stronger norms of codification may ease identification and acquisition of routines. Second, teams vary in the degree to which they have contact with, or are interdependent with other similar teams or other parts of their organization. Teams with more external contact may be exposed to more new routines, and as a result, this may relate to knowledge acquisition and interruptions. External contact was measured using a 4-item scale answered using a 7-point Likert-type scale: (1) this team depends on other teams to get our work done, (2) members of this team have frequent contact with members of other similar teams, (3) this team often must interact with other teams to complete our tasks, and (4) members of this team regularly attend meetings with members of other similar teams. The reliability for this scale was 0.76 (alpha). Team scores were created by averaging individual members' scale scores by team. Third, the size of teams in my sample widely varied. Smaller teams may have different internal processes and knowledge-related dynamics, so I included team size as a control variable. Finally, over time, routines may become more engrained, therefore, time together may influence knowledge acquisition. As a result, I included a control variable for length of time team has existed.

\section{Aggregate Measures}

I created several variables by aggregating individuallevel data. In such aggregated variables, within-group agreement should be apparent (Ancona and Caldwell 1992, p. 655, George 1990, p. 110, Goodman et al. 1990), therefore, I calculated an interrater agreement score $\left(r_{W G}\right)$ for each composite variable. This measure ranges from 0 (no agreement) to 1 (complete agreement) (James et al. 1984, 1993). Others have suggested 0.60 as an acceptable cutoff criterion (Glick 1985). The interrater agreement was 0.85 for knowledge transfer effort, 0.67 for contact, and 0.71 for number of interruptions, suggesting adequate agreement for aggregation. ${ }^{5}$

\footnotetext{
${ }^{5}$ Others have also suggested that an indication of convergence within teams is an intraclass correlation (ICC) greater than 0 with a corresponding ANOVA $F$-statistic that is statistically significant
}

\section{Analyses and Results}

Table 1 reports the descriptive statistics and correlations. The average length of time teams existed was 4.81 years, with a minimum of 2 months and a maximum of 18 years. Teams reported an average of 2.69 interruption types with a minimum of 0 and a maximum of 11 . Bivariate relationships indicate that interruptions and knowledge transfer effort are positively related $(r=0.31, p<0.01)$; interruptions and knowledge acquisition are positively related $(r=$ $0.38, p<0.001)$; and knowledge transfer effort and knowledge acquisition are positively related $(r=0.43$, $p<0.001$ ). Also interesting to note, external contact and knowledge transfer effort are positively related $(r=0.34, p<0.01)$, as are interruptions and external contact $(r=0.30, p<0.01)$. Teams with more external contact may have more permeable boundaries, opening up the opportunity for both more knowledge acquisition activity and interruptions.

I tested the hypotheses using ordinary least squares (OLS) regression. Hypothesis 1 predicted that interruptions would positively influence knowledge transfer effort. The coefficient for interruptions was positive and significant $(b=0.09, p<0.05)$, supporting Hypothesis 1. Hypothesis 2 predicted that the number of interruptions would positively influence knowledge acquisition. This was supported $(b=0.06$, $p<0.001$ ).

Hypothesis 3 predicted that knowledge transfer effort would mediate the relationship between interruptions and knowledge acquisition. Analyzing mediation involves three steps (Baron and Kenny 1986, Kenny et al. 1998, MacKinnon and Dwyer 1993). The first step is to establish that the independent variable (here interruptions) influences the final dependent variable (here knowledge acquisition). This step was supported in the above test of Hypothesis 2. The second step is to demonstrate that the independent variable (interruptions) influences the mediator

(Edmondson 1999, Kenny and LaVoie, 1985). In all cases, the ICC is greater than 0 and the $F$-statistic is significant. Intraclass correlation coefficients were generated using one-way analysis of variance on the individual-level data with team membership as the independent variable and the scales scores as the dependent variables. 
ZELLMER-BRUHN

Interruptive Events and Team Knowledge Acquisition

Table 1 Descriptive Statistics and Correlations

\begin{tabular}{lcrrrrrrrrr}
\hline Variable & Alpha & Mean & s.d. & Min & Max & 1 & 2 & 3 & 4 & 5 \\
\hline 1. Team size & N/A & 10.56 & 3.15 & 3.00 & 21.00 & 1.00 & & & & \\
2. External contact & 0.76 & 3.87 & 0.90 & 1.50 & 5.69 & $-0.32^{* *}$ & 1.00 & & \\
3. Knowledge transfer effort & 0.96 & 2.35 & 0.61 & 1.00 & 4.25 & 0.03 & $0.34^{* *}$ & 1.00 & \\
4. Team exist & N/A & 4.81 & 4.13 & 0.17 & 18.33 & 0.01 & -0.07 & -0.05 & 1.00 & \\
5. Interruptions & 0.70 & 2.69 & 1.72 & 0.00 & 11.00 & -0.10 & $0.30^{* *}$ & $0.31^{* *}$ & 0.05 & 1.00 \\
6. Knowledge acquisition & N/A & 0.24 & 0.22 & 0.00 & 1.00 & 0.12 & 0.03 & $0.43^{* * *}$ & 0.03 & $0.38^{* * *}$ \\
\hline
\end{tabular}

a Length of time team has existed in years.

$n=90$ teams.

$t$-tests are two-tailed.

${ }^{*} p<0.05,{ }^{* *} p<0.01,{ }^{* * *} p<0.001$.

(knowledge transfer effort). This step was supported in the above test of Hypothesis 1. The third step is to demonstrate that the mediator (knowledge transfer effort) influences the dependent variable, controlling for the independent variable (interruptions). If, in step three, the effect of interruptions on knowledge acquisition is no longer significant when knowledge transfer effort is in the model, this indicates complete or full mediation (Baron and Kenny 1986, Kenny et al. 1998). The coefficient for knowledge transfer effort was positive and significant $(b=0.14, p<0.001)$, indicating a main effect of knowledge transfer effort on knowledge acquisition. With knowledge transfer effort in the equation, the coefficient for interruptions remained positive and significant $(b=0.04, p<0.001)$ but both the coefficient size and the corresponding $t$-statistic decreased ( $b=0.06$ vs. $b=0.04$, and $t=$ 4.12 vs. $t=3.40$, respectively). I tested the statistical significance of the mediated effect by dividing the mediated effect by its standard error, resulting in a $z$-score (Baron and Kenny 1986, Kenny et al. 1998, MacKinnon and Dwyer 1993). For this model testing Hypothesis 3, the mediated effect is statistically significant $(z=2.51)$. These results do not support full mediation, but rather partial mediation (Baron and Kenny 1986, Kenny et al. 1998, p. 260, James and Brett 1984), supporting Hypothesis 3. Table 2 presents the hypotheses test results.

None of the control variables influenced either dependent variable with the exception that external contact significantly influenced knowledge acquisition effort $(b=0.23, p<0.01)$.

\section{Exploratory Analyses}

In addition to the hypotheses tests, I conducted three categories of exploratory analyses to further examine the relationship between interruptions and knowledge acquisition: (1) checking for a nonlinear influence of interruptions on knowledge acquisition, (2) examining whether different types of interruptions had different effects on knowledge acquisition, and (3) examining interview results to consider the sources of knowledge.

I checked for a nonlinear influence of interruptions by including a squared term for interruptions in the full model for knowledge acquisition. The squared term for interruptions was positive and significant $(b=0.01, p<0.05)$. When the squared term was included in the model, the linear term was no longer significant. This result suggests that the influence of interruptions on knowledge acquisition increases at an increasing rate. To further investigate this finding and check my results for robustness, I dropped one significant outlier (a team with 11 interruptions). Without the outlier, the squared term was no longer statistically significant, but all the coefficients for the variables in the original hypothesis, including the linear term for interruptions, remained positive and significant.

My next set of exploratory analyses examined the effects of different types of interruptions. The hypotheses tested above addressed the number of interruptions, not whether qualitatively different types of interruptions may have different effects on knowledge acquisition. To explore this latter question, I first 
ZELLMER-BRUHN

Interruptive Events and Team Knowledge Acquisition

Table 2 Regression Results

\begin{tabular}{|c|c|c|c|c|c|}
\hline \multirow[b]{2}{*}{ Variable } & \multicolumn{2}{|c|}{$\begin{array}{l}\text { Knowledge transfer effort } \\
\text { (Hypothesis 1) }\end{array}$} & \multicolumn{3}{|c|}{$\begin{array}{l}\text { Knowledge acquisition } \\
\text { (Hypotheses } 2 \text { and } 3 \text { ) }\end{array}$} \\
\hline & B & B & B & B & B \\
\hline \multirow[t]{2}{*}{ External contact } & $0.28^{* *}$ & $0.23^{* *}$ & 0.03 & 0.00 & -0.03 \\
\hline & $(0.08)$ & $(0.08)$ & $(0.03)$ & $(0.03)$ & $(0.03)$ \\
\hline \multirow[t]{2}{*}{ Team exist } & -0.00 & -0.01 & 0.00 & 0.00 & 0.00 \\
\hline & $(0.02)$ & $(0.02)$ & $(0.01)$ & $(0.01)$ & $(0.01)$ \\
\hline \multirow[t]{2}{*}{ Organization A } & -0.17 & -0.15 & -0.03 & -0.01 & 0.02 \\
\hline & $(0.28)$ & $(0.27)$ & $(0.11)$ & $(0.10)$ & $(0.09)$ \\
\hline \multirow{2}{*}{ Organization B } & -0.03 & -0.06 & 0.07 & 0.05 & 0.06 \\
\hline & $(0.20)$ & $(0.20)$ & $(0.08)$ & $(0.07)$ & $(0.07)$ \\
\hline \multirow[t]{2}{*}{ Team size } & 0.01 & 0.02 & 0.01 & 0.01 & 0.01 \\
\hline & $(0.03)$ & $(0.03)$ & $(0.01)$ & $(0.01)$ & $(0.01)$ \\
\hline \multirow[t]{2}{*}{ Interruptions ${ }^{1}$} & & $0.09 *$ & & $0.06^{* * *}$ & $0.04^{* * * *}$ \\
\hline & & $(0.04)$ & & $(0.01)$ & $(0.01)$ \\
\hline \multirow[t]{2}{*}{ Knowledge transfer effort ${ }^{1}$} & & & & & $0.14^{* * *}$ \\
\hline & & & & & $(0.04)$ \\
\hline$R^{2}$ & 0.14 & 0.19 & 0.05 & 0.22 & 0.34 \\
\hline Adjusted $R^{2}$ & 0.09 & 0.13 & -0.01 & 0.16 & 0.28 \\
\hline$F$ & $2.58^{*}$ & $3.16^{* *}$ & 0.80 & $3.63^{* *}$ & $5.74^{* * * *}$ \\
\hline$\Delta R^{2}$ & & 0.05 & & 0.17 & 0.12 \\
\hline$N$ & 86 & 86 & 85 & 85 & 85 \\
\hline
\end{tabular}

conducted a principle components exploratory factor analysis of the original interruption items to see whether some interruption types grouped together. The rotated (varimax) solution suggested four factors. These four factors account for $54 \%$ of the explained variance. Based on this exploration, I used eight of the original items to create multi-item interruption categories. ${ }^{6}$ I examined the items in each factor to name the four variables corresponding to the four factors: (1) task/technology related (two items, e.g., changes in tools or machines); (2) structure related (three items, e.g., changes in team or organizational structure), (3) redirection (two items, e.g., formal planning session); and (4) products (one item, e.g., new products or services). In the interest of exploration, I also included in regression analyses four remaining interruption items that did not cleanly load on any of the four factors as individual interruption type variables: breaks in regularly scheduled work (one

\footnotetext{
${ }^{6}$ Factor loadings on items assigned to each factor ranged from 0.62 to 0.81 on their respective factors, and 0.31 or less on other factors. In most cases, loadings on other factors were much lower than 0.30 .
}

item), performance problems (one item), high performance (one item), and "other unusually disruptive events" (one item). Thus, in the exploratory analyses, eight variables were substituted in place of the single variable of number of interruptions that was used in the hypotheses tests. I duplicated the analyses for the hypotheses tests using these eight types interruptions in place of the single interruption measure.

These exploratory analyses suggest that different types of interruptions differently influence knowledge transfer effort and knowledge acquisition. Redirection interruptions and high-team performance positively influenced knowledge transfer effort $(b=0.75, p<0.01$; and $b=0.71, p<0.05$, respectively). Task/technology related interruptions negatively influenced knowledge transfer effort $(b=-0.60, p<0.10)$. However, while redirection, high-team performance, and task/technology interruptions influence knowledge transfer effort, they do not influence knowledge acquisition. Changes in team structure positively influenced knowledge acquisition $(b=0.22, p<0.10)$. The 0.10 cutoff level (two-tailed) 
is reasonable for these exploratory analyses given the difficultly of detecting significance with a large number of parameters (13-14) and a relatively small number of observations. "Other unusually disruptive events" negatively influenced knowledge acquisition $(b=-0.26, p<0.05)$. Thus, different types of interruptions may play distinctly different roles in team knowledge acquisition processes.

Finally, using qualitative data, I investigated the sources of knowledge noted by teams. I found that teams tend to acquire knowledge from their "neighborhood." The most common sources noted were other similar teams in their organization, other departments in the organization, other geographic locations in the organization, and company websites. The sources least commonly noted were other organizations outside the industry or other organizations within the industry. While not empirically linked to knowledge acquisition effort or interruptions, this information provides additional insight into the nature of knowledge acquisition in teams.

\section{Discussion}

This study examined the relationship between interruptions and team knowledge acquisition. The results suggest that interruptions spur knowledge transfer effort, and knowledge transfer effort increases the acquisition of new routines. Interruptions influenced knowledge acquisition both directly and by increasing knowledge transfer effort. Their influence through knowledge transfer effort supports prior theory that suggests interruptions trigger active cognitive processing, which, in turn, stimulates changes such as acquiring new routines. In addition to their influence through knowledge transfer effort, interruptions had a direct, positive relationship with knowledge acquisition. The "pause" created by an interruption may be enough for the team to notice new knowledge and acquire it, even without deliberate search effort.

Furthermore, exploratory analyses suggest that different types of interruptions may have different influence on knowledge transfer effort and knowledge acquisition. Teams experiencing redirection and high performance reported higher knowledge transfer effort. Redirection involves formal planning and incorporating new members, and as such may focus teams on their practices-to consider whether they are in need of change. High performance may invoke the opportunity for slack search, or it may be the case that high-performing teams are compelled to actively examine their routines so they can identify what is working to codify it for potential transfer to teams with performance problems. In other words, the interruption resulting from high performance may not prompt teams to examine their routines because of dissatisfaction or the need to acquire new routines, but rather to understand them more fully in terms of replicating what works. Different interruptions influenced knowledge acquisition. Specifically, structural changes positively influenced acquisition. Disruptive events that did not fall within the other interruption categories identified in previous research had a negative relationship with knowledge acquisition. One explanation for this negative relationship may be that interruptions identified by team members as "unusually disruptive" may be low frequency events, ${ }^{7}$ that, when they do occur, are so disruptive to a team that the emphasis is no longer on how to do what they do better (by acquiring a new practice), but rather how to survive.

These findings have implications for three theoretical domains: (1) knowledge management, (2) team-level routines, and (3) team-boundary spanning. First, this research is one of the first empirical studies of team-level knowledge acquisition, and to my knowledge, the first direct study of interruptions and knowledge acquisition. The results suggest that knowledge-acquisition activities, acquiring routines in this case, are common at the team level, and that teams look outside their boundaries for new knowledge. This supports the notion that teams are a critical focal point in organizational knowledge management (Argote 1999, Nonaka 1994, Nonaka and Takeuchi 1995).

This study follows other recent work in explicating distinct parts of the knowledge transfer process (e.g., Hansen 1999). The knowledge management

\footnotetext{
${ }^{7}$ In this sample, the interruption item "other unusually disruptive events" had the lowest frequency of occurrence of the 13 different interruption items.
} 
literature has been criticized for ill-defined concepts (Okhuysen and Eisenhardt 2002, Eisenhardt and Santos 2002). This study addresses this critique by detailing one mechanism in the knowledge acquisition process, and by examining one aspect of knowledge transfer-knowledge acquisition-at the team level. The finding that some types of interruptions may influence knowledge acquisition effort, and not knowledge acquisition, and vice versa further supports the usefulness of distinguishing distinct knowledge processes. Future research should also include knowledge sharing and integration.

Finally, this study suggests other future research directions in knowledge management. In particular, it indicates a need to further develop theory on the timing of knowledge acquisition. Knowledge of the type studied here (i.e., practices) may be available much of the time, but teams may be more or less receptive to acquiring it at specific times (e.g., in the presence of or following interruptions). Presently, the knowledge management literature has focused much attention on characteristics of the knowledge (e.g., Grant 1996, Kogut and Zander 1992, Szulanski 1996) with comparatively little attention on timing.

In addition to the knowledge management literature, these results also support previously untested theory concerning group routines. Gersick and Hackman (1990) posited that interruptive events may be necessary to impel teams to break habitual routines. Their reasoning, and others (Langer 1989, Louis and Sutton 1991), is that routine action is conducted in a more or less "mindless" manner, and will continue unless something occurs providing the impetus to examine routines. In this study, teams faced with more interruptive events in a particular month reported greater attention to their practices and to the search for new routines. This attention, in turn, positively influenced knowledge acquisition. These results extend previous research demonstrating that interruptions influence internal adaptation (Gersick 1988, 1989; Okhuysen and Eisenhardt 2002) to suggest that they also influence external knowledge acquisition.

Finally, this study adds to the literature on team-boundary spanning (Ancona 1990, Ancona and Caldwell 1992) by examining a potential antecedent to a specific boundary-spanning activity—knowledge acquisition. While not specifically examining knowledge transfer, team boundary-spanning research suggests that teams that are isolated from their external environments have poorer performance (Ancona and Caldwell 1992). Further insight to the boundaryspanning process may have important consequences for team performance. Little attention has been given to the triggers of boundary spanning. Prior research focused mainly on describing boundary-spanning activities and demonstrating that they influence performance. This study suggests that interruptive events increase boundary spanning, at least as it relates to knowledge acquisition. Future research should examine the role of interruptions in other boundary-spanning activities. In addition, the timing of various boundary-spanning activities matters. For example, Ancona and Caldwell (1992) found that teams that engaged in scouting (e.g., gathering information, exploring project possibilities) for prolonged periods, rather than limiting them to early periods of a project, had decreased performance. The timing of knowledge acquisition may affect performance. Future research should examine whether the relationship varies with the timing of interruptions and knowledge acquisition.

This study also has implications for practice. These results suggest that interruptions should not always be viewed as negative, with attempts made to suppress their impact. They may play an important role in knowledge acquisition. To the extent that managers desire knowledge acquisition in their teams, they may actively attempt to manage interruptive events, both in terms of number and different kinds of interruptions. Alternatively, as the use of knowledge transfer infrastructure like intranets increases, managers may attempt to time the presentation of new knowledge on these sites with interruptive events to increase the chances that team members notice them. In addition, qualitative results suggest that teams tend to focus their search and knowledge acquisition in "local" areas. Team leaders may want to consider whether these are the best sources for new knowledge. If so, they can work to reinforce existing channels to enhance this type of knowledge transfer. For example, increasing team-to-team contact and interdependence may enhance team-level knowledge acquisition. 
While this research makes a contribution to theory and practice, it is not without limitations. Future research should examine in greater detail the cognitive and behavioral reactions of team members to interruptions. For example, I did not measure whether respondents viewed interruptions as positive or negative. Perhaps, positive interruptions may have different effects than negative interruptions. Furthermore, interruptions may reach a point of diminishing returns-too many interruptions may result in so much disruption that no knowledge acquisition activity is undertaken. I did not find evidence of diminishing returns in this sample, but future research using more extensive sets of interruptions and alternative methods may uncover such limits. For example, it may be the case that diminishing returns occur only at high levels of interruption, which may be a relatively rare occurrence in the field, or that teams actively manage their acknowledgement or reactions to certain types of interruptions to prevent the too-manyinterruptions scenario from happening.

The knowledge acquisition measure was also somewhat crude. The dichotomous variable did not allow for detailed understanding of the knowledge acquired by the teams-only whether or not such acquisition occurred. For example, do interruptions encourage teams to acquire simplistic, quick-fix routines? If so, what might lead a team to adopt more complex routines? Future research should incorporate more detailed measures of the knowledge acquiredperhaps using multiple sources and methods-to address this open question.

Finally, I did not measure performance of teams in this study. To truly understand the impact of interruptions on teams, future research should examine both knowledge acquisition as well as interruptions to enable the test of the relative influence of the two on team performance.

\section{Conclusion}

Team knowledge acquisition concerns both researchers and practitioners because it may be beneficial for teams to change their routines (Edmondson 1999, Gersick and Hackman 1990). Teams can learn in two ways: (1) through internal adaptation, or
(2) through knowledge acquisition from external sources. This study examined the latter and found interruptive events play an important role in knowledge acquisition by influencing knowledge acquisition activities. Team knowledge acquisition is likely to become even more important as organizations face dynamic, complex environments, and continue to increase the use of teams to complete work in these environments. Future research may gain by including interruptive events in studies of knowledge transfer.

\section{Acknowledgments}

The author thanks Linda Argote, Ramon Aldag, Phil Bromiley, Dan Forbes, Cristina Gibson, Bill McEvily, Ray Reagans, Myles Shaver, and two anonymous reviewers for helpful comments on a previous version of this manuscript. This research substantially benefited from the funding provided by National Science Foundation Grant SBR 96-31748, the Multinational Implementation of Teams Project.

\section{References}

Adcock, W. O. 1971. Time, one more time. California Management Rev. 14(2) 28-32.

Ancona, D. G. 1990. Outward bound: Strategies for team survival in an organization. Acad. Management J. 33 334-365.

_ D. F. Caldwell. 1992. Bridging the boundary: External activity and performance in organizational teams. Admin. Sci. Quart. 37 634-665.

Andrasik, F., J. S. Heimberg. 1982. Self-management procedures. Handbook of Organizational Behavior Management. L. W. Frederiksen, ed. Wiley-Interscience, New York, 219-247.

Argote, L. 1999. Organizational Learning. Creating, Retaining, and Transferring Knowledge. Kluwer Academic Publishers, Boston, MA.

Ashforth, B., Y. Fried. 1988. The mindlessness of organizational behaviors. Human Relations 41(4) 305-329.

Bandura, A. 1977. Social Learning Theory. Prentice-Hall, Englewood Cliffs, NJ.

Baron, R. M., D. A. Kenny. 1986. The moderator-mediator variable distinction in social psychological research: Conceptual, strategic and statistical considerations. J. Personality Soc. Psych. 51 1173-1182.

Brown, S. L., K. Eisenhardt. 1998. Competing on the Edge. Harvard Business School Press, Boston, MA.

Cellier, J., H. Eyrolle. 1992. Interface between switched tasks. Ergonomics 35(1) 25-36.

Cohen, M. D., J. G. March, J. P. Olsen. 1972. A garbage can model of organizational choice. Admin. Sci. Quart. 17(1) 1-25.

Conner, K. R. 1991. A historical comparison of resource-based theory and five schools of thought within industrial organization economics: Do we have a new theory of the firm? J. Management 17 121-154. 
- C. K. Prahalad. 1996. A resource-based theory of the firm: Knowledge versus opportunism. Organ. Sci. 7(5) 477-502.

Conover, W. J. 1980. Contingency tables, Chapter 4. Practical Nonparametric Statistics. 2nd ed. John Wiley and Sons, New York.

Cyert, R. M., J. G. March. 1963. A Behavioral Theory of the Firm. Premtice Hall, Englewood Cliffs, NJ.

Devine, D. J., L. D. Clayton, J. L. Philips, B. B. Dunford, S. B. Melner. 1999. Teams in organizations. Prevalence, characteristics, and effectiveness. Small Group Res. 30(6) 678-711.

Dougherty, D. 1992. Interpretive barriers to successful product innovation in large firms. Organ. Sci. 3(May) 179-202.

Doz, Y. L. 1996. The evolution of cooperation in strategic alliances: Initial conditions or learning processes? Strategic Management J. 17(Special Issue) 55-85.

Edmondson, A. 1999. Psychological safety and learning behavior in work teams. Admin. Sci. Quart. 350-383.

—. 2001. Disrupted routines: Team learning and new technology implementation in hospitals. Admin. Sci. Quart. 46 685-716.

Eisenhardt, K. M., F. M. Santos. 2002. Knowledge-based view: A new theory of strategy? A Pettigrew, H. Thomas, R. Whittington, eds. Handbook of Strategy and Management. Sage Publications, London, U.K., 139-164.

Epple, D., L. Argote, R. Devadas. 1991. Organizational learning curves: A method for investigating intraplant transfer of knowledge acquired through learning by doing. Organ. Sci. 2 58-70.

Feldman, M. S. 2000. Organizational routines as a source of continuous change. Organ. Sci. 11 611-629.

George, J. 1990. Personality, affect, and behavior in groups. J. Appl. Psych. 75(2) 107-116.

Gersick, C. J. G. 1988. Time and transition in work teams: Toward a new model of group development. Acad. Management J. 31(1) 9-41.

- 1989. Marking time: Predictable transitions in task groups. Acad. Management J. 32(2) 274-309.

- 1991. Revolutionary change theories: A multilevel exploration of the punctuated equilibrium paradigm. Acad. Management Rev. 16(1), 10-36.

— , J. R. Hackman. 1990. Habitual routines in task-performing groups. Organ. Behavior Human Decision Processes 47 65-97.

Glick, W. H. 1985. Conceptualizing and measuring organizational and psychological climate: Pitfalls in multilevel research. Acad. Management Rev. 10 601-616.

Goodman, P. S., E. C. Ravlin, M. Schminke. 1990. Understanding groups in organizations. L. L. Cummings, B. M. Staw, eds. Leadership, Participation, and Group Behavior. JAI Press, Greenwich, CT, 323-385.

Gordon, J. 1992. Work teams: How far have they come? Training 29 59-65.

Grant, R. M. 1996. Toward a knowledge-based theory of the firm. Strategic Management J. 37(1) 9-45.

Hansen, M. T. 1999. The search-transfer problem: The role of weak ties in sharing knowledge across organizational subunits. Admin. Sci. Quart. 42 716-749.
Hedlund, G. 1994. A model of knowledge management and the $\mathrm{N}$-form corporation. Strategic Management J. 15 73-91.

Huber, G. 1991. Organizational learning: The contributing processes and the literatures. Organ. Sci. 2(1) 88-115.

James, L. R., J. M. Brett. 1984. Mediators, moderators, and tests of mediation. J. Appl. Psych. 69 307-321.

— , R. G. Demaree, G. Wolf. 1984. Estimating within-group interrater reliability with and without response bias. J. Appl. Psych. 69 85-98.

1993. rWG: An assessment of within group interrater agreement. J. Appl. Psych. 78 306-339.

Kelly, J. R., J. E. McGrath. 1985. Effects of time limits and task types on task performance and interaction of four-person groups. J. Personality Soc. Psych. 49 395-407.

Kenny, D. A., L. LaVoie. 1985. Separating individual and group effects. J. Personality Soc. Psych. 48 339-348.

_ D. A. Kashy, N. Bolger. 1998. Data analysis in social psychology. D. Gilbert, S. Fiske, G. Lindzey, eds. The Handbook of Social Psychology, Vol. 1, 4th ed. McGraw-Hill, Boston, MA, 233-265.

Kirmeyer, S. L. 1988. Coping with competing demands: Interruption and the type A pattern. J. Appl. Psych. 73(4) 621-629.

Kleiner, B. H. 1992. The art of handling many things at once. Managerial Auditing J. 7(6) 24.

Kogut, B., U. Zander. 1992. Knowledge of the firm, combinative capabilities, and the replication of technology. Organ. Sci. 4 383-397.

Langer, E. J. 1979. Rethinking the role of thought in social interactions. J. H. Harvey, W. J. Ickes, R. F. Kidd, eds. New Directions in Attribution Theory, vol. 2. Erlbaum, Hillsdale, NJ.

- 1989. Minding matters: The mindlessness/mindfulness theory of cognitive activity. L. Berkowitz, ed. Advances in Experimental Social Psychology. Academic Press, New York.

Lessard, D. R., S. Zaheer. 1996. Breaking the silos: Distributed knowledge and strategic responses to volatile exchange rates. Strategic Management J. 17(7) 513-534.

Levitt, B., J. G. March. 1988. Organizational learning. Ann. Rev. Soc. 14 319-340.

Liang, D. W., R. Moreland, L. Argote. 1995. Group versus individual training and group performance: The mediating role of transactive memory. Personality Soc. Psych. Bull. 21(4) 384-393.

Louis, M. R., R. I. Sutton. 1991. Switching cognitive gears: From habits of mind to active thinking. Human Relations 44(1) 55-76.

Lucco, F. J. 1994. Effective time management. Appraisal J. 62(4) 580-587.

MacKinnon, D. P., J. H. Dwyer. 1993. Estimating mediated effects in prevention studies. Evaluation Rev. 17(2) 144-158.

Manz, C. C. 1986. Self-leadership: Toward an expanded theory of self-influence processes in organizations. Acad. Management Rev. 585-600.

March, J. G., H. A. Simon. 1958. Organizations. John Wiley, New York.

McGrath, J. E. 1984. Groups, Interaction, and Performance. Prentice Hall, Englewood Cliffs, NJ.

Meyer, A. D. 1982. Adapting to environmental jolts. Admin. Sci. Quart. 27(4) 515-537. 


\section{ZELLMER-BRUHN}

Interruptive Events and Team Knowledge Acquisition

Miner, A. S., S. J. Mezias. 1996. Ugly duckling no more: Pasts and futures of organizational learning research. Organ. Sci. 7(1) 88-100.

Mohrman, S. A., S. G. Cohen, A. M. Mohrman Jr. 1995. Designing Team-Based Organizations: New Forms for Knowledge Work. Jossey-Bass, San Francisco, CA.

Moreland, R. L., L. Argote, R. Krishnan. 1996. Socially shared cognition at work: Transactive memory and group performance. J. L. Nye, A. M. Brower, eds. What's So Social About Social Cognition? Social Cognition Research in Small Groups. Sage Publications, Thousand Oaks, CA, 57-84.

Nelson, R. R., S. G. Winter. 1982. An Evolutionary Theory of Economic Change. Harvard University Press, Cambridge, MA.

Nonaka, I. 1994. A dynamic theory of organizational knowledge creation. Organ. Sci. 5(1) 14-37.

— H. Takeuchi. 1995. The Knowledge-Creating Company. Oxford University Press, New York.

Okhuysen, G. A., K. M. Eisenhardt. 1997. Creating opportunities for change: How formal problem solving interventions work. Acad. Management Conf., Cincinnati, $\mathrm{OH}$.

$\ldots$, - 2002. Integrating knowledge in groups: How formal interventions enable flexibility. Organ. Sci. 13(4) 370-386.

Pentland, B. T., H. H. Rueter. 1994. Organizational routines as grammars of action. Admin. Sci. Quart. 39(3) 484-510.

Perlow, L. 1999. The time famine: Toward a sociology of work time. Admin. Sci. Quart. 44 57-81.

Rousseau, D. M. 1985. Issues of level in organizational research: Multi-level and cross-level perspectives. L. L. Cummings, B. M. Staw, eds. Res. Organ. Behavior 7 1-37.

Ruggles, R. 1998. The state of the notion: Knowledge management in practice. California Management Rev. 40(3) 80-89.

Scott, W. R. 1992. Organizations, Rational, Natural and Open Systems, 3rd ed. Prentice Hall, Englewood Cliffs, NJ.
Szulanski, G. 1996. Exploring internal stickiness: Impediments to the transfer of best practices within the firm. Strategic Management J. 17(Winter Special Issue) 27-43.

Thompson, L., E. Peterson, S. W. Brodt. 1996. Team negotiation: An examination of integrative and distributive bargaining. J. Personality Soc. Psych. 70(1) 66-78.

Tyre, M. J., W. J. Orlikowski. 1994. Windows of opportunity: Temporal patterns of technological adaptation in organizations. Organ. Sci. 5(1) 98-118.

_ L. Perlow, N. Staudenmayer, C. Wasson. 1996. Time as a trigger for organizational change. Acad. Management Conf. Cincinnati, $\mathrm{OH}$

Virany, B., M. Tushman. E. Romanelli. 1992. Executive succession and organization outcomes in turbulent environments: An organization learning approach. Organ. Sci. 3(1) 72-91.

Wageman, R. 1995. Interdependence and group effectiveness. Admin. Sci. Quart. 40 145-180.

Wegner, D. M. 1986. Transactive memory: A contemporary analysis of the group mind. G. Mullen, G. Geothals, eds. Theories of Group Behavior. Springer-Verlang, New York, 185-208.

Weick, K. E. 1990. Technology as Equivoque: Sensemaking in new technologies. P. S. Goodman, L. S. Sproull, eds. Technology and Organizations. Jossey-Bass, San Francisco, CA, 1-44.

—. 1992. The Social Psychology of Organizing. Addison-Wesley, Reading, MA.

1993. The collapse of sensemaking in organizations: The Mann Gulch disaster. Admin. Sci. Quart. 38(4) 628-652.

Weiss, H. M., D. R. Ilgen. 1985. Routinized behavior in organizations. J. Behavioral Econom. 57-67.

Winter, S. G. 1996. Organizing for continuous improvement. Evolutionary theory meets the quality revolution. M. D. Cohen, L. S. Sproull, eds. Organ. Learn. Sage Publications, Thousand Oaks, CA, 460-483.

Accepted by Linda Argote, William McEvily, and Ray Reagans; received February 28, 2001. This paper was with the author 6 months for 2 revisions. 